\title{
Impact of Smoking and Diabetes Mellitus on Clinico-Bacterio-Radiological Profile of Pulmonary Koch's Patients
}

\author{
Surinder Pal Singh ${ }^{1}$, Kailash Meena², Chungath Jain ${ }^{2}$ \\ ${ }^{1}$ Associate Professor, Department of Pulmonary Medicine, Government Medical College, Patiala, ${ }^{2}$ Department of Pulmonary Medicine, Government Medical \\ College, Patiala.
}

\section{Abstract}

Background: Both smoking and diabetes are attributed to be strongly linked with pulmonary tuberculosis. The significance of the study lies in assessing severity of manifestations in pulmonary tuberculosis patients due to smoking and diabetes. Subjects and Methods: This is a cross sectional observational study among patients presenting to Department of Tuberculosis and Chest Diseases, Government Medical College, Patiala. 200 Patients were enrolled in this study who are sputum smear positive pulmonary kochs patients already on ATT and admitted in this department were evaluated by clinical history, blood and radiological investigations and the data was statistically analyzed. Results: Non smoker non diabetic group had maximum of females, $\mathrm{n}=28(56 \%)$, whereas purely diabetic study group has maximum of males, $n=30(60 \%)$. The total number of patients whose sputum showed bacterial culture was $19(9.5 \%)$. In the patients having both diabetes and smoking as risk factor there was maximum culture positivity, $\mathrm{n}=6$ (31.5\%)and most common organism isolated was klebsiella pneumonia, $\mathrm{n}=3(50 \%)$, Klebsiella was also the most common organism isolated overall, $\mathrm{n}=10(62.5 \%)$. Conclusion: The combination of smoking and diabetes can lead to serious disease, sputum positivity and complications.

Keywords: Diabetes Mellitus, Smoking, Pulmonary Tuberculosis.

Corresponding Author: Dr. Surinder Pal Singh, Associate Professor, Department of Pulmonary Medicine, Government Medical College, Patiala.

Email: drsurinderpal09@gmail.com

Received: December 2019

Accepted: January 2020

Introduction

TB is one of the most important problems in India, with 1.98 million new cases per year, comprising over $20 \%$ of the global total for incident cases. ${ }^{[1]}$ Chronic exposure to tobacco, as well as to a number of environmental pollutants, impairs the normal clearance of secretion on the tracheo bronchial mucosal surface and may thus allow the causative organism Mycobacterium tuberculosis, to escape the first level of host defenses which prevent bacilli from reaching the alveoli. ${ }^{[2]}$

Smoke also impairs the function of pulmonary alveolar surfactants. ${ }^{[3]}$ Nicotine is hypothesized to act directly on nicotine acetylcholine receptors on macrophages to decrease production of intracellular tumor necrosis factor and thus impair killing of M. tuberculosis. ${ }^{[4]}$ These effects of smoking on pulmonary host defense support a causal link between smoke exposure and either an increased risk of acquiring TB or progression of TB.

In a recently conducted study it was found that 'Ever smokers' were more likely to have experienced cough, dyspnea, cavity, milliary lung involvement, positive sputum culture and poor outcomes of TB. In both current smokers and ex-smokers TB was associated with more extensive lung disease, lung cavitations and positive sputum bacteriology. Patients who continue to smoke, therefore, pose a risk not only to themselves, but also to every other person simultaneously exposed to their infection and cigarette smoke. ${ }^{[5-9]}$

Diabetes mellitus (DM) is also associated with an increased risk of TB disease. ${ }^{[10]}$ According to a recent systematic review, among cohort studies, people with DM had approximately three times the risk of developing TB disease as people without . The global burden of DM is rising; the prevalence is estimated to reach 438 million by 2030, and more than $80 \%$ of the adult cases will be in newly developed or developing countries. The convergence of these two epidemics may lead to an increased incidence of TB disease, especially in low and middle income countries with increasing numbers of people with DM and prevalent TB disease. Diabetic TB patients have an increased risk of treatment failure, death and recurrent TB compared with non-diabetic TB patients. ${ }^{[1,12]}$ DM also influences the manifestations of TB. It has been reported that diabetic TB patients have more symptoms, ${ }^{[13]}$ are more likely to be smear-positive, ${ }^{[14,15]}$ and have an increased frequency of cavitary lesions compared with non-diabetic TB patients. ${ }^{[16]}$ In a recent study smokers had more than a 2 -fold increased risk of pre-treatment positive smears in both non-diabetic and diabetic TB patients and diabetic smokers had more than a 5-fold increased risk of pre-treatment positive smears 
than did non-diabetic non-smokers. Furthermore, the increased frequency in positive smears was mainly of a high positivity grade, indicating remarkable joint effects of diabetes and smoking that increased the risk of transmission of TB. ${ }^{[17]}$

This study is an effort to investigate joint effects and interactions between the influences of smoking and diabetes on TB.

\section{Subjects and Methods}

This is a cross sectional and observational study where a total of 200 sputum smear positive pulmonary kochs patients already on ATT admitted in Department of chest and TB diseases, whose clinical history, sputum bacteriological investigation, smoking and diabetic status, blood investigations, radiological patterns analysed for the purpose of studying varying manifestations due to smoking and diabetes.50 diabetic patients, 50 smokers,50 patients who are both smoker and diabetics,50 patients who are neither smoker or diabetic are compared on basis of clinical symptoms, sputum AFB grading and radiological severity.

Clinical symptoms include fever, cough-productive and nonproductive, haemoptysis, breathlessness, loss of weight and loss of appetite were assessed. Diabetic control assessed by fasting blood sugar and HbA1c levels.

An ever-smoker is defined as one who had smoked the equivalent of at least one cigarette a day for a period of 1 year. An ex-smoker is defined as an ever-smoker who had stopped smoking for at least 1 year before the current TB episode, and a current smoker as an ever-smoker who was still smoking or had stopped smoking for less than 1 year. Patients who did not fulfil the criterion of an ever-smoker are classified as never-smokers.

Sputum investigations include sputum AFB smear by fluorescent microscopy, gram stain and pyogenic culture.

For this study sputum grading done by fluorescent microscopy with $0.1 \%$ auramine stain and grading is as follows. ${ }^{[18]}$

\begin{tabular}{|l|l|}
\hline Grade & No of AFB seen \\
\hline SCANTY & $1-19 / 40$ fields \\
\hline $1+$ & $20-199 / 40$ fields \\
\hline $2+$ & $5-50 / 1$ field \\
\hline $3+$ & $>50 / 1$ field \\
\hline
\end{tabular}

Blood investigations include haematological profile- $\mathrm{Hb}$, TLC, DLC, Platelet count along with FBS, HbA1C for diabetic status. Radiological severity was assessed by Chest X-Ray. The radiological severity of the disease was assessed based on the guidelines of National TB Association of USA. ${ }^{[19]}$ Recordings of abnormal opacity of the lung parenchyma included location (right-upper, rightlower, left-upper, or left-lower) and the extent of disease (minimal, moderately-advanced, or far advanced).

The extent of disease was estimated based on the sum of all areas of abnormality in which a boundary of abnormal opacity could be drawn.

- Minimal lesions were defined as an area less than that above a horizontal line across the 2 nd chondro sternal conjunction of one lung.

- Moderately advanced lesions were defined as an area greater in size than the minimal lesions but smaller than that of one entire lung.

- Far advanced lesions were defined as an area equivalent to or greater than one lung

The data was collected at end of study period and statistically analysed.

\section{Inclusion Criteria}

- All pulmonary kochs patients already on ATT diagnosed by smear positive report.

- Patients included in this study are selected from four groups-smoker, diabetic, both smoker and diabetic, nonsmoker and non-diabetic.

\section{Exclusion Criteria}

- Pulmonary kochs patients clinico-radiologically diagnosed.

- Pulmonary kochs patients diagnosed by molecular techniques CBNAAT, Line probe assay and culture.

\section{$\underline{\text { Aims \& Objectives }}$}

- To study association of TB manifestations severity in pulmonary kochs patients due to smoking and diabetes

- To study the joint effect of diabetes and smoking status on clinico-bacterio-radiological manifestations of pulmonary kochs

- To study the various radiological patterns in chest $\mathrm{x}$ ray in pulmonary kochs patients due to impact of diabetes

- To identify the main micro-organisms co-infecting a pulmonary kochs patient with smoking and diabetes

- To identify the association of blood sugar control in diabetic pulmonary kochs patients with severity of TB manifestations

\section{Results}

Out of total 200 patients the most common presentation of tuberculosis was fever which accounted for 80 percentage of patients $(n=160)$ followed by cough, 76.5 percentage $(\mathrm{n}=153)$ [Table 1]

Table 1: Symptom Profile of Patients Enrolled
\begin{tabular}{|l|l|l|}
\hline Symptom & No of patients having symptom & Percentage \\
\hline Fever & 160 & 80 \\
\hline Cough & 153 & 76.5 \\
\hline Haemoptysis & 15 & 7.5 \\
\hline Breathlessness & 57 & 28.5 \\
\hline Loss of appetite & 144 & 72 \\
\hline Loss of weight & 144 & 72 \\
\hline Total & 200 & 100 \\
\hline
\end{tabular}

Haemoptysis which is a dreaded complication of pulmonary kochs had its maximum prevalence in diabetic smoker group, 4 percentage $(n=8)$

In the study conducted it was found out that there was only one female smoker after including both smoking groups under study (smoker non diabetic and smoker diabetic) Non smoker non diabetic group had maximum of females, 
$\mathrm{n}=28(56 \%)$, whereas purely diabetic study group has maximum of males, $n=30(60 \%)$. [Table 2]

\begin{tabular}{|l|l|l|l|}
\hline Table 2: Gender Distribution in Diabetic Study Group \\
\hline Group & Males & Females & Total \\
\hline Number of patients & 30 & 20 & 50 \\
\hline Percentage & 60 & 40 & 100 \\
\hline
\end{tabular}

On comparison of social background for patients having atleast one risk factor (smoker, diabetic, smoker and diabetic) it was found that maximum population was from rural background, $n=92(61.33 \%)$ [Table 3]

Table 3: Social Background Distribution Among Study
Population
\begin{tabular}{|l|l|l|l|}
\hline Group & Rural & Urban & Total \\
\hline Number of patients & 92 & 58 & 150 \\
\hline Percentage & 61.33 & 31.87 & 100 \\
\hline
\end{tabular}

Across the two groups who smoked it was found that there was a majority of ex-smokers, $n=59(59 \%)$.Average smoking index of smoking non diabetic group was found to be 194.8 and average pack years was found to be 14.15.Average smoking index of smoker diabetic group was found to be 300 and average pack years found to be 20 . In the smoker diabetic group of patients majority of the patients had a sputum AFB grading of $3+, \mathrm{n}=27(54 \%)$ followed by $2+, n=13(26 \%)$ [Table 4 ]

\section{Table 4: Distribution Of Patients In Diabetic Smoker Group} By Sputum Grading

\begin{tabular}{|l|l|l|}
\hline Sputum grading & Number of patients & Percentage \\
\hline Scanty & 3 & 6 \\
\hline $1+$ & 7 & 14 \\
\hline $2+$ & 13 & 26 \\
\hline $3+$ & 27 & 54 \\
\hline Total & 50 & 100 \\
\hline
\end{tabular}

The total number of patients whose sputum showed bacterial culture was $19(9.5 \%)$. In the patients having both diabetes and smoking as risk factor there was maximum culture positivity, $\mathrm{n}=6(31.5 \%)$ and most common organism isolated was klebsiella pneumonia, $\mathrm{n}=3$ (50\%), Klebsiella was also the most common organism isolated overall, $n=10$ $(62.5 \%)$. [Table 5 \& Figure 1]

Table 5: Percentage of Organisms Isolated By Culture

\begin{tabular}{|l|l|l|}
\hline Organism & Number & $\begin{array}{l}\text { Percentage of isolated } \\
\text { organisms }\end{array}$ \\
\hline E coli & 3 & 15.7 \\
\hline Klebsiella pneumonia & 10 & 52.7 \\
\hline Acinetobacter & 2 & 10.6 \\
\hline Pneumococcus & 1 & 5.3 \\
\hline $\begin{array}{l}\text { Pseudomonas } \\
\text { aeruginosa }\end{array}$ & 3 & 15.7 \\
\hline Total & 19 & 100 \\
\hline
\end{tabular}

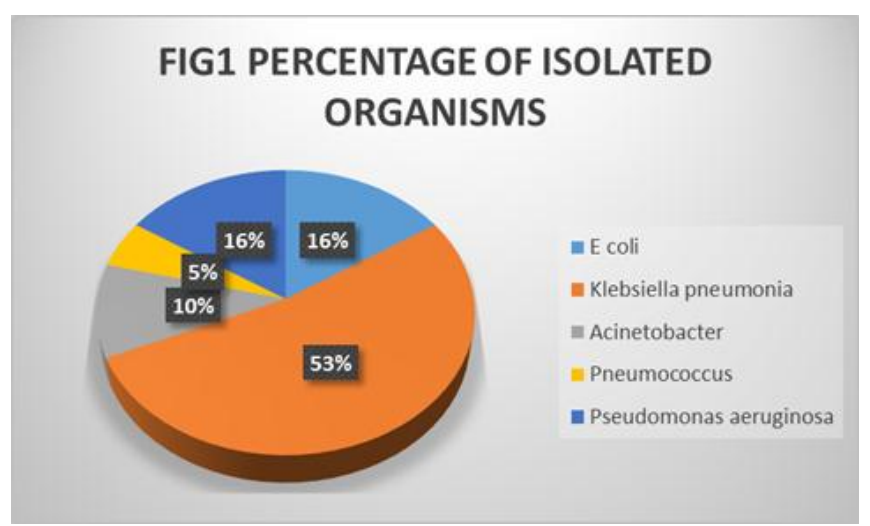

On comparison of total leukocyte count among patients it was found that raised count $(>15000)$ was found maximum among patients of pure smoker group $n=10(20 \%)$. [Table 6]

Table 6: Distribution Of Patients Based On Leukocyte Count
\begin{tabular}{|l|l|l|}
\hline Total leukocyte count & Number of patients & Percentage \\
\hline$<11000$ & 25 & 50 \\
\hline $11000-15000$ & 15 & 30 \\
\hline$>15000$ & 10 & 20 \\
\hline total & 50 & 100 \\
\hline
\end{tabular}

Out of total 200 patients only 2 subjects were HIV positive both were from smoker diabetic population (1\%)

When data of radiological involvement was analysed it was found that more radiological involvement was found in groups having atleast one risk factor and maximum patients with far advanced radiological lesion was found to be from group having both smoking and diabetes, $\mathrm{n}=30 \quad(60 \%)$ followed by diabetic group, $\mathrm{n}=27(54 \%)$ and smoker group, $\mathrm{n}=21(42 \%)$. [Table 7]

Table 7: Percentage of Patients With Far Advanced Lesion

\begin{tabular}{|l|l|l|}
\hline Group & $\begin{array}{l}\text { Number of patients with far } \\
\text { advanced lesion }\end{array}$ & Percentage \\
\hline Smoker & 21 & 42 \\
\hline $\begin{array}{l}\text { Smoker and } \\
\text { diabetic }\end{array}$ & 30 & 60 \\
\hline Diabetic & 27 & 54 \\
\hline $\begin{array}{l}\text { Non smoker non } \\
\text { diabetic }\end{array}$ & 14 & 28 \\
\hline Total & 50 & 100 \\
\hline
\end{tabular}

FIG 2 PERCENTAGE OF PATIENTS WITH FAR ADVANCED LESION

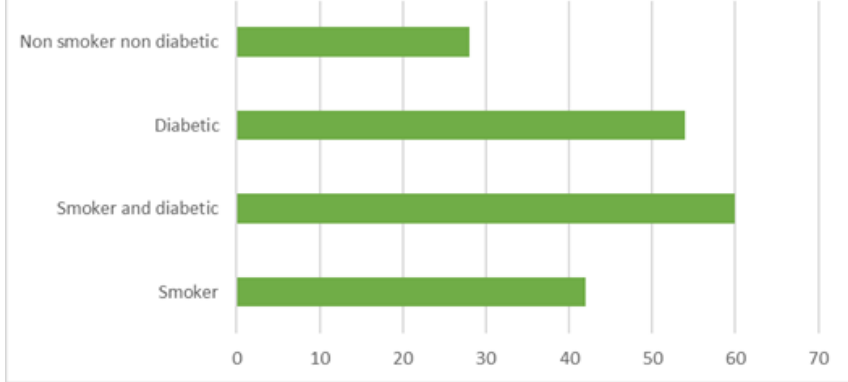

Out of radiological lesions consolidation was the common radiological lesion, $\mathrm{n}=101(50.5 \%)$,followed by cavity with 
consolidation, $\mathrm{n}=80(40 \%)$. Out of 2 HIV positive patients one had cavity with consolidation and one presented with miliary disease. [Table 8]

$\begin{aligned} & \text { Table 8: Distribution of Types of Radiological Lesion amo } \\
& \text { Study Poopulation }\end{aligned}$
\begin{tabular}{|l|l|l|}
\hline Radiological lesion & Number of patients & Percentage \\
\hline Pneumothorax & 5 & 2.5 \\
\hline Hydropneumothorax & 3 & 1.5 \\
\hline Consolidation & 101 & 50.5 \\
\hline Cavity and consolidation & 80 & 40 \\
\hline Pleural effusion & 8 & 4 \\
\hline Miliary pattern & 3 & 1.5 \\
\hline Total & 200 & 100 \\
\hline
\end{tabular}

Out of the total diabetic population only 20 percentage $(n=20)$ afforded $\mathrm{HbA1C}$ and out of these patients 15 patients had good diabetic control. [Table 9]

Table 9: Diabetic Control Among Patients Enrolled

\begin{tabular}{|l|l|l|}
\hline Criteria & Number of patients & Percentage \\
\hline HbA1C performed & 20 & 20 \\
\hline Diabetic control & 15 & 15 \\
\hline Total & 100 & 100 \\
\hline
\end{tabular}

\section{Discussion}

It was observed during our study that the maximum reported symptom of pulmonary Kochs was fever and not cough, which may highlight the limitation of our current screening symptom of cough more than 2 weeks as cough seem to be frequently overlooked by patients especially from rural areas with poor access to healthcare facilities. Haemoptysis observed mostly in group with both diabetes and smoking which may imply the rapid progression of disease in presence of these risk factors.

Rural population constituted majority of the study population, mainly due to the urban population unwillingness to disclose information about disease status and unwillingness to do the required investigations for this study. This highlights to need for greater awareness about the among urban population even though they are having higher literacy levels.

The finding that majority were ex smokers in the smoking group denoted that tobacco smoking leaves a long term residual impact on lung health and leave a person predisposed to pulmonary Kochs

Both the HIV patients had far advanced lesion on X ray which depicts the advanced disease that occurs in patients with TB HIV coinfections independent of any other risk factors

The high proportion of sputum $3+$ patients ,maximum culture positivity and maximum proportion of far advanced lesions on Chest $\mathrm{X}$ ray in the diabetic smoker group denotes the additive synergy of these two risk factors but our study failed to demonstrate the increased risk factor association of diabetes or smoking. ${ }^{[17]}$

One limitation of this study was that in the smoker group there was only one female leading to gender bias and poor results. Another limitation was that only 20 percentage of the patients enrolled underwent $\mathrm{HbA} 1 \mathrm{C}$ investigation due to poor affordability and hence poor assessment of glycemic control of the patients. The main strength of this study is the presence of a good control group.

\section{Conclusion}

Even though many studies have been conducted on the impact of smoking and diabetes on TB causation and disease progression but not on the joint effect of both these factors. The conclusion is that combination of smoking and diabetes can lead to serious disease, sputum positivity and complications.

\section{References}

1. TB India 2013. Revised National Tuberculosis Control Programme. Annual Status Report; Introduction. 2013;12.

2. Pierson T, LearmonthPierson S, Pinto D, van Hoek ML. Cigarette smokeextract induces differential expression levels of beta defensin peptides in human alveolar epithelial cells. TobInduc Dis 2013;11:10

3. Domagala Kulawik J. Effects of cigarette smoke on the lung and systemic immunity. J PhysiolPharmacol 2008;59Suppl 6:19-34.

4. Wang H, Yu M, Ochani M, Amella CA, Tanovic M, Susarla S, et al.Nicotinic acetylcholine receptor alpha7 subunit is an essential regulator of inflammation. Nature 2003;421:384-8.

5. Leung CC, Yew WW, Chan CK, Chang KC, law WS, Lee SN, et al. Smoking adversely affects treatment response, outcome and relapse in tuberculosis EurRespir J. 2015;45:583-5.

6. Leung CC, Yew WW, Chan CK, Tam CM, Lam CW, Chang KC, et al. Smoking and tuberculosis in Hong Kong. Int $\mathrm{J}$ Tuberc Lung Dis. 2003;7:980-6.

7. Altet-Gómez MN, Alcaide J, Godoy P, Romero MA, Hernández del Rey I. Clinical and epidemiological aspects of smoking and tuberculosis: a study of 13038 cases. Int J Tuberc Lung Dis. 2005;9:430-6.

8. Wang JY, Hsueh PR, Jan IS, Lee LN, Liaw YS, Yang PC, et al. The effect of smoking on tuberculosis: different patterns and poorer outcomes. Int J Tuberc Lung Dis. 2007;11:143-9.

9. Wampande EM, Mupere E, Debanne SM, Asiimwe BB, Nsereko M, Mayanja $\mathrm{H}$, et al. Long-term dominance of Mycobacterium tuberculosis Uganda family in peri-urban Kampala-Uganda is not associated with cavitary disease. BMC Infect Dis. 2013;14712334/13/484.

10. Jeon CY, Murray MB. Diabetes mellitus increases the risk of active tuberculosis: a systematic review of 13 observational studies. PLoS Med. 2008;5(7)

11. Baker MA, Harries AD, Jeon CY, Hart JE, Kapur A, Lönnroth K, et al. The impact of diabetes on tuberculosis treatment outcomes: a systematic review. BMC Medicine. 2011;1741-7015/9/81.

12. Jiménez-Corona ME, Cruz-Hervert LP, García-García L, FerreyraReyes L, Delgado-Sánchez G, Bobadilla-del-Valle $M$, et al. Association of diabetes and tuberculosis: impact on treamtent and post-treatment outcomes. Thorax. 2013;68:214-20.

13. Alisjahbana B, Sahiratmadja E. The Effect of Type 2 Diabetes Mellitus on the Presentation and Treatment Response of Pulmonary Tuberculosis. Clin Infect Dis. 2007;45:428-35.

14. Wang CS, Yang CJ, Chen HC, Chuang SH, Chong IW, Hwang JJ, et al. Impact of type 2 diabetes on manifestations and treatment outcome of pulmonary tuberculosis. Epidemiol Infect. 2009;137:203-10.

15. Chang JY, Dou HY, Yen CL, Wu YH, Huang RM, Lin HJ, et al, Effect of type 2 Diabetes Mellitus on the clinical severity and treatment outcome in patients with pulmonary tuberculosis: a potential role in the emergence of multidrug-resistance. J Formos Med Assoc. 2011;110(6):372-8.

16. Chiang C-Y, Lee J-J, Chien S-T, Enarson DA, Chang Y-C, Chen Y-T, et al. Glycemic control and radiographic manifestations of tuberculosis in diabetic patients. PLoS ONE. 2014;9(4) 
17. Kuan-Jen Bai, Jen-JyhLee,Shun-TienChien,Chi-Won Suk,Chen-Yuan Chiang. The Influence of Smoking on Pulmonary Tuberculosis in Diabetic and Non-Diabetic Patients.PLoS One. 2016; 11(6)

18. Treatment and operational guidelines 2016. New Dehi: Central TB Division, Directorate General of Health Services Ministry of Health \&
Family Welfare; 2016. Annexure-2;136-7

19. Falk A, O'Connor JB, Pratt PC. Classification of pulmonary tuberculosis.In: Diagnostic Standards and Classification of Tuberculosis. 12th ed.New York: National Tuberculosis and Respiratory Disease Association;1969

Copyright: (C) the author(s), 2020. It is an open-access article distributed under the terms of the Creative Commons Attribution License (CC BY 4.0), which permits authors to retain ownership of the copyright for their content, and allow anyone to download, reuse, reprint, modify, distribute and/or copy the content as long as the original authors and source are cited.

How to cite this article: Singh SP, Meena K, Jain C. Impact of Smoking and Diabetes Mellitus on Clinico-Bacterio-Radiological Profile of Pulmonary Koch's Patients. Asian J. Med. Res. 2020;9(1):PM09-PM13.

DOI: dx.doi.org/10.47009/ajmr.2020.9.1.PM3

Source of Support: Nil, Conflict of Interest: None declared. 